\title{
HUBUNGAN TEGANGAN INPUT KOMPRESOR DAN TEKANAN REFRIGERAN TERHADAP COP MESIN PENDINGIN RUANGAN
}

\author{
Eko Budiyanto \\ Program Studi Teknik Mesin Fakultas Teknik Universitas Muhammadiyan Metro \\ Jl. KH. Dewantara No. 116 Metro Telp. (0725) 45932-42445 Kode Pos 34111 \\ eko_budiyanto99@yahoo.com
}

\begin{abstract}
Abstrak
Listrik merupakan sumber energi utama pada peralatan elektronik terutama pada AC ( air conditioner), sehingga besar kecilnya tegangan listrik sangat mempengaruhi kinerja mesin. Selain tegangan listrik, kerja mesin pendingin juga dipengaruhi oleh tekanan refrigeran. Penelitian ini bertujuan untuk mengetahui hubungan tegangan input kompresor dan tekanan refrigeran terhadap COP serta untuk mengetahui perubahan temperatur yang terjadi pada evaporator dan kondensor karena pengaruh tegangan input kompresor dan tekanan refrigeran. Penelitian dilakukan dengan cara melakukan pengambilan data pada AC split dengan tegangan input kompresor yang divariasikan $200 \mathrm{~V}, 210 \mathrm{~V}, 220 \mathrm{~V}$, dan $230 \mathrm{~V}$ (tekanan refrigeran $70 \mathrm{Psi}$ ). Selain memvariasikan tegangan input kompresor juga memvariasikan pada tekanan refrigeran yaitu pada tekanan refrigeran 30 Psi, 50 Psi, dan 70 Psi (tegangan input kompresor 220V). Dari hasil perhitungan data diperoleh nilai COP pada tegangan input kompresor 200V, 210V, 220V, dan 230V masing-masing adalah 16,87; 17,855; 19,865; dan 18,23. COP pada tekanan refrigeran 30 Psi, 50 Psi, dan 70 Psi masing-masing adalah 14,980; 17,296; 19,865. Dari besarnya nilai COP pada beberapa varian percobaan didapatkan hasil bahwa tegangan input kompresor yang paling baik adalah $220 \mathrm{~V}$ dan tekanan refrigeran yang paling baik adalah $70 \mathrm{Psi}$.
\end{abstract}

Kata Kunci : AC, kompresor, tekanan, refrigeran , COP

\section{PENDAHULUAN}

Sekarang ini penggunaan mesin pendingin semakin luas pada masyarakat dari rumah tinggal, perkantoran, hotel, mobil, rumah sakit, dan industri. Pemakaian mesin pendingin bervariasi dari yang berkapasitas kecil, sedang, hingga besar.

Mesin pendingin adalah pengaplikasian dari hukum termodinamika yang kemudian muncul istilah refrigerasi dan pengkondisian udara. Bidang refrigerasi dan pengkondisian udara saling berkaitan, tetapi masing-masing mempunyai ruang lingkup yang berbeda. Pengkondisian udara berupa pengaturan suhu, pengaturan kelembaban dan kualitas udara sedangkan refrigerasi digunakan untuk kebutuhan proses tertentu seperti pendinginan untuk rumah tangga, keperluan umum, dan industri antara lain meliputi : cold storage, ice scating rinks, desalting, pemrosesan makanan dan minuman, industri kimia, dan industri manufaktur.

Dalam proses pendinginan diperlukan input energi dari luar. Input energi ini berupa energi listrik. Daya listrik berperan penting sebagai sumber energi dan besarnya daya listrik dipengaruhi oleh besar tegangan listrik yang terjadi sehingga besar tegangan listrik dapat berpengaruh terhadap putaran kompresor yang tentu saja berpengaruh pula terhadap kualitas pendinginannya.

Mesin pendingin adalah sebuah sistem dengan siklus kerja tertutup, karena berhubungan dengan tekanan fluida yang berada di dalamnya yaitu refrigeran. Refrigeran memiliki banyak jenis, berbeda jenis refrigeran akan berbeda pula besar tekanan yang dibutuhkan dalam proses pendinginan. Selain tegangan listrik, besar tekanan refrigeran juga memberikan pengaruh terhadap hasil pendinginan. Semakin rendah tekanan refrigeran akan membuat kerja kompresor menjadi ringan tetapi hasil pendinginannya akan menurun.

Untuk mengetahui pengaruh dari tegangan listrik dan tekanan refrigeran terhadap kinerja mesin pendingin tersebut maka perlu adanya perhitungan data yang menunjukkan hubungan tegangan listrik dan tekanan refigeran terhadap $\mathrm{COP}(s)$ mesin pendingin ruangan dengan menvariasikan tegangan input kompresor AC dan menurunkan tekanan refrigerannya. 


\section{LANDASAN TEORI}

\section{Pengertian Refrigrasi}

Refrigerasi adalah sebuah alat siklus yang prinsip kerjanya berdasarkan hukum termodinamika kedua atas pernyataan Clausius yang dapat diungkapkan sebagai berikut : " Adalah tidak mungkin membuat sebuah alat yang beroperasi dalam sebuah siklus tanpa adanya efek dari luar untuk mentransfer panas dari media bertemperatur rendah ke media bertemperatur tinggi" (Filipno Harahap, 1991)

Pernyataan tersebut menjelaskan sistem dapat menghasilkan perpindahan kalor dari sumber yang dingin ke sumber yang lebih panas asalkan terdapat masukan berupa kerja atau energi.

Prinsip utama mesin refrigerasi adalah untuk menurunkan temperatur agar materi atau ruangan dapat terjaga temperaturnya sesuai dengan kebutuhan dan kenyamanan yang dikehendaki.

\section{Siklus Refrigerasi Kompresi Uap}

Mesin refrigerasi dengan kompresi uap merupakan sistem yang terbanyak digunakan dalam proses refrigerasi. Prinsip dasar uap ini adalah uap ditekan kemudian diembunkan setelah itu tekanannya diturunkan agar cairan itu akan menguap kembali karena menyerap panas lingkungan. Dalam sistem kompresi diperlukan 4 komponen, yaitu kompresor, kondensor, katup ekspansi dan evaporator.

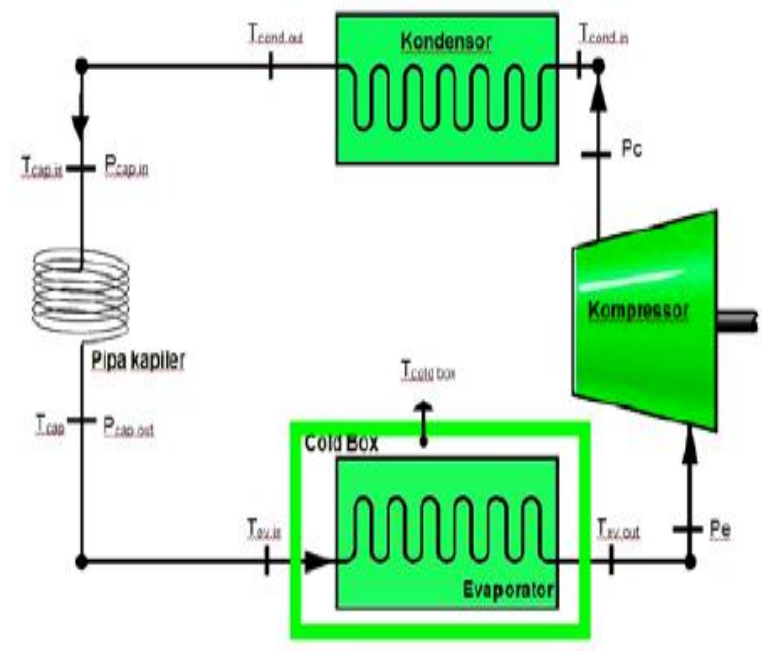

Gambar 1. Siklus Refrigerasi Kompresi Uap

\section{Sistem Pengkondisian Udara}

Sistem pengkondisian udara/sistem tata udara adalah suatu proses mendinginkan/memanaskan udara sehingga dapat mencapai suhu dan kelembaban yang diinginkan/dipersyaratkan. Selain itu, mengatur aliran udara dan kebersihannya.

Sistem penyegaran udara pada umumnya dibagi menjadi dua golongan utama yaitu :

1) Penyegaran udara untuk kenyamanan Menyegarkan udara ruangan untuk memberikan kenyamanan bagi penghuni yang berada didalam ruangan. Kondisi udara yang dirasakan nyaman oleh tubuh manusia adalah berkisar antara :

Suhu dan kelembaban $\quad: 20^{\circ} \mathrm{C}$ hingga $26^{\circ} \mathrm{C}, 45 \%$ hingga $55 \%$

Kecepatan udara $: 0,25 \mathrm{~m} / \mathrm{s}$

2) Penyegaran udara untuk industri.Menyegarkan udara ruangan karena diperlukan oleh proses, bahan, peralatan atau barang yang ada di dalamnya.

\subsection{Perhitungan Dalam Sistem Refrigerasi}

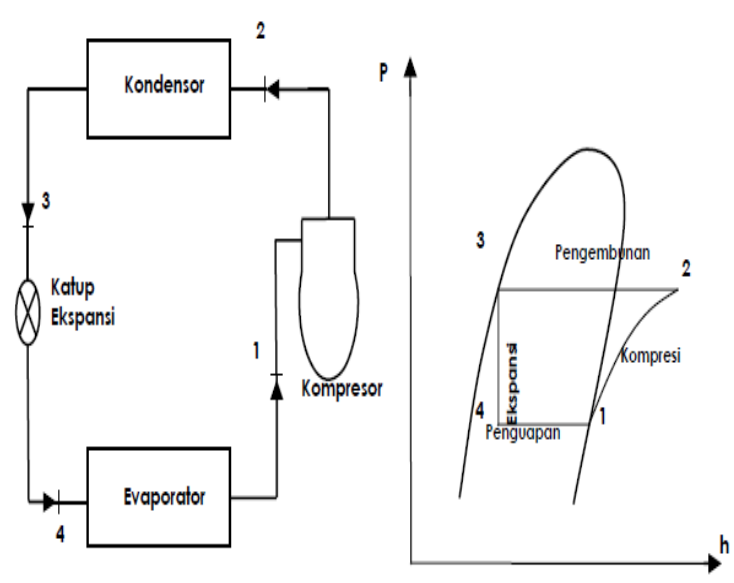

Gambar 2. Diagram P - h siklus kompresi uap ideal

1. Proses kompresi (1-2)

$Q_{w}=h_{2}-h_{l}$

(Ridwan, 1994)

Dimana :

$Q_{w}=$ Besarnya kerja kompresor, $(\mathrm{kJ} / \mathrm{kg})$

$h_{l}=$ Entalpi refrigeran saat masuk kompresor, $(\mathrm{kJ} / \mathrm{kg})$

$h_{2}=$ Entalpi refrigeran saat keluar kompresor, $(\mathrm{kJ} / \mathrm{kg})$

2. Proses kondensasi (2-3)

$Q_{c}=h_{2}-h_{3}$

(Ridwan,1994)

Dimana :

$Q_{c}=$ Besarnya panas dilepas di kondensor, $(\mathrm{kJ} / \mathrm{kg})$ 


$$
\begin{aligned}
h_{2}= & \begin{array}{l}
\text { Entalpi refrigeran saat masuk } \\
\text { kondensor, }(\mathrm{kJ} / \mathrm{kg})
\end{array} \\
h_{3}= & \begin{array}{l}
\text { Entalpi refrigeran saat keluar } \\
\text { kondensor, }(\mathrm{kJ} / \mathrm{kg})
\end{array}
\end{aligned}
$$

3. Proses expansi (3-4)

$$
h_{3}=h_{4}
$$

(Ridwan,1994)

Dimana :

$$
\begin{aligned}
h_{3}= & \begin{array}{l}
\text { Entalpi refrigeran saat keluar } \\
\text { kondensor, }(\mathrm{kJ} / \mathrm{kg})
\end{array} \\
h_{4}= & \begin{array}{l}
\text { Entalpi refrigeran } \\
\text { evaporator, }(\mathrm{kJ} / \mathrm{kg})
\end{array}
\end{aligned}
$$

4. Proses evaporasi (4-1)

$$
Q_{e}=h_{1}-h_{4} \quad \text { (Ridwan, 1994) }
$$

Dimana :

$$
\begin{aligned}
Q_{e}= & \text { Besarnya panas yang diserap di } \\
& \text { evaporator, }(\mathrm{kJ} / \mathrm{kg}) \\
h_{1} \quad & \text { Entalpi refrigeran saat keluar } \\
& \text { evaporator, }(\mathrm{kJ} / \mathrm{kg}) \\
h_{4}= & \text { Entalpi refrigeran saat masuk } \\
& \text { evaporator, }(\mathrm{kJ} / \mathrm{kg})
\end{aligned}
$$

\section{METODE PENELITIAN \\ Desain Alat Uji}

Unit indoor ac dipasang di dalam ruangan, unit outdoor ac dipasang di luar ruangan, kabel suplai tegangan listrik yang menuju unit outdoor ac dihubungkan dengan input regulator voltase. Output regulator voltase dihubungkan dengan input tegangan listrik unit outdoor ac. Pada tekanan refrigeran standar tegangan listrik divariasikan. Pada tegangan listrik normal tekanan refrigeran divariasikan.

\section{Tahap Pengujian Alat}

Siapkan alat ukur dan unit ac, pasang unit indoor ac pada ruangan, pasang unit outdoor ac, pasang 2 buah pipa penghubung antara indoor unit dan outdoor unit, pastikan pipa terpasang dengan benar dan rapat, pasang kabel suplai tegangan listrik dari indoor unit agar terhubung dengan input regulator voltase, hubungkan output regulator voltase dengan input teganga listrik outdoor unit ac, pasang gauge manifold pada nepel pengisisan, sebelum unit ac diisi refrigeran terlebih dulu divakum dengan mesin vakum, isi refrigeran sampai pada tekanan standar (70 psi), pasang pengukur temperatur pada pipa masuk evaporator, pipa keluar evaporator, pipa masuk kondensor, pipa keluar kondensor, pipa masuk kompresor, hembusan kondensor, hembusan evaporator, dan pada ruangan. Operasikan sistem, dan atur tegangan pada regulator voltase pada level $220 \mathrm{v}$, catat perubahan temperatur yang ditunjukkan oleh alat ukur setiap 10 menit sampai temperatur ruangan pada kondisi nyaman yaitu $23^{\circ} \mathrm{c}$, lakukan pengukuran yang sama untuk level $200 \mathrm{v}, 210$ $\mathrm{v}, 230 \mathrm{v}$ pada regulator voltase, setelah pengambilan data pada variasi tegangan, regulator diatur pada tegangan normal $(220 \mathrm{v})$, turunkan tekanan menjadi 50 psi, lakukan pengambilan data, turunkan tekanan refrigeran pada 30 psi, lakukan pengambilan data.

\section{HASIL DAN PEMBAHASAN}

\section{Hasil Pengujian Alat}

Dari hasil pengujian dan pengukuran diperoleh beberapa data diantaranya adalah : beban pendinginan, hasil pengukuran pada tegangan $200 \mathrm{~V}$, hasil pengukuran pada tegangan $210 \mathrm{~V}$, hasil pengukuran pada tegangan $220 \mathrm{~V}$, dan hasil pengukuran pada tegangan $230 \mathrm{~V}$. Beban pendinginan adalah 2 orang duduk tenang tanpa aktivitas dengan perolehan kalor $2 \times 100$ watt $=200$ watt, 1 unit laptop 14 " dengan daya 50 watt, 1 buah lampu neon dengan daya 18 watt. Total beban pendinginan $=(200+50+18)$ watt $=268$ watt. ( Supratman Hara,1982 ).

\section{Pembahasan}

Penyegar udara atau yang biasa disebut Air Conditioner $(A C)$ dirancang dengan mempergunakan bahan atau unsur pendingin (Refrigeran) yang mempunyai sifat mekanis yang dimasukkan ke dalam suatu sistem peredaran udara untuk diedarkan melalui komponen-komponen utama penyegar yang telah dibuat sedemikian rupa sehingga dapat menghisap atau menyerap suhu panas udara di dalam suatu ruangan dan memindahkan suhu panas udara tersebut keluar ruangan, sehingga tercapailah suatu penyegar udara yang ideal.

Kompresor sebagai jantung dari sistem tata udara yang berguna untuk menghisap uap refrigeran dari ruang penampung uap. Ketika di dalam penampung uap, tekanannya diusahakan agar tetap rendah, supaya refrigeran senantiasa berada dalam keadaan uap dan bersuhu rendah. 
Lalu ketika di dalam kompresor, tekanan refrigeran dinaikkan sehingga memudahkan pencairannya kembali. Energi yang diperlukan untuk kompresi diberikan oleh motor listrik yang menggerakkan kompresor. Maka daya listrik memberikan pengaruh yang cukup besar terhadap kerja kompresor.

Pada kondisi ideal, besar tegangan listrik adalah 220 V. Namun pada kenyataannya terkadang kondisi tegangan listrik tidak selalu konstan $220 \mathrm{~V}$. Tegangan listrik dibawah $220 \mathrm{~V}$ menyebabkan kompresor bekerja terlalu lamban sehingga ketercapaian waktu pendinginan ruangan yang ideal yaitu 23 ${ }^{0} \mathrm{C}$ membutuhkan waktu yang lebih lama.

Pada pengolahan data dan perhitungan, tampak bahwa besar tegangan input kompresor memberikan pengaruh yang besar terhadap COP mesin pendingin. Untuk tegangan input kompresor dibawah $220 \mathrm{~V}$ yaitu $210 \mathrm{~V}$ dan $200 \mathrm{~V}$, semakin kecil tegangan input kompresor membuat nilai COP menurun masing-masing 17,855 dan 16,87 . Nilai COP paling tinggi didapat pada input tegangan kompresor $220 \mathrm{~V}$ yaitu mencapai 19,865; selanjutnya pada tegangan diatas $220 \mathrm{~V}$ yaitu $230 \mathrm{~V}$ COP kembali turun menjadi 18,23.

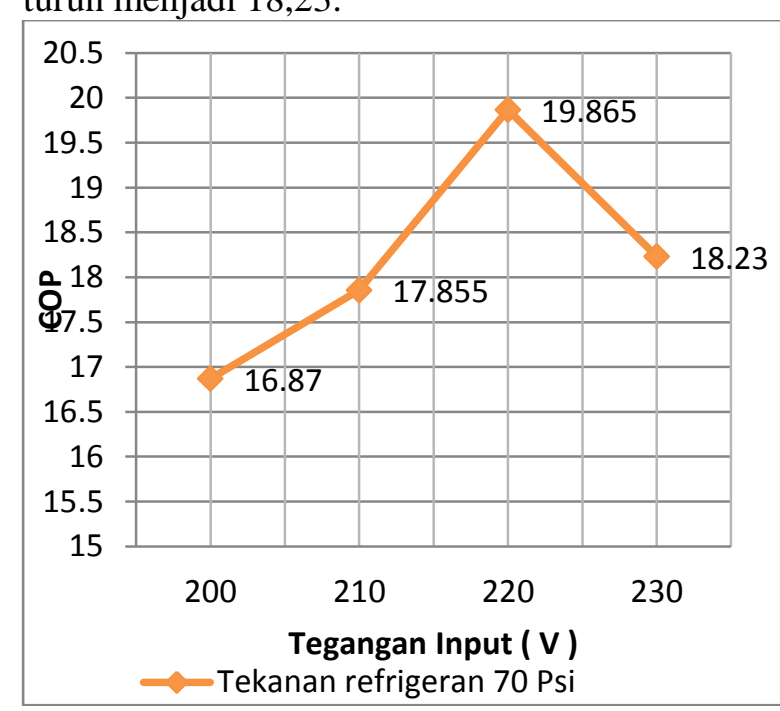

Gambar 3. Diagram nilai COP pada tegangan input kompresor yang berbeda

Selain pada tegangan input kompresor, penurunan COP juga ditunjukkan pada saat terjadi penurunan tekanan refrigeran. Semakin kecil nilai tekanan refrigeran menyebabkan nilai COP menurun. Hasil pengolahan data dan perhitungan menunjukkan nilai COP sebesar 19,865 pada tekanan refrigeran 70Psi, 17,296 pada tekanan refrigeran 50Psi, dan 14,980 pada tekanan refrigeran 30Psi.

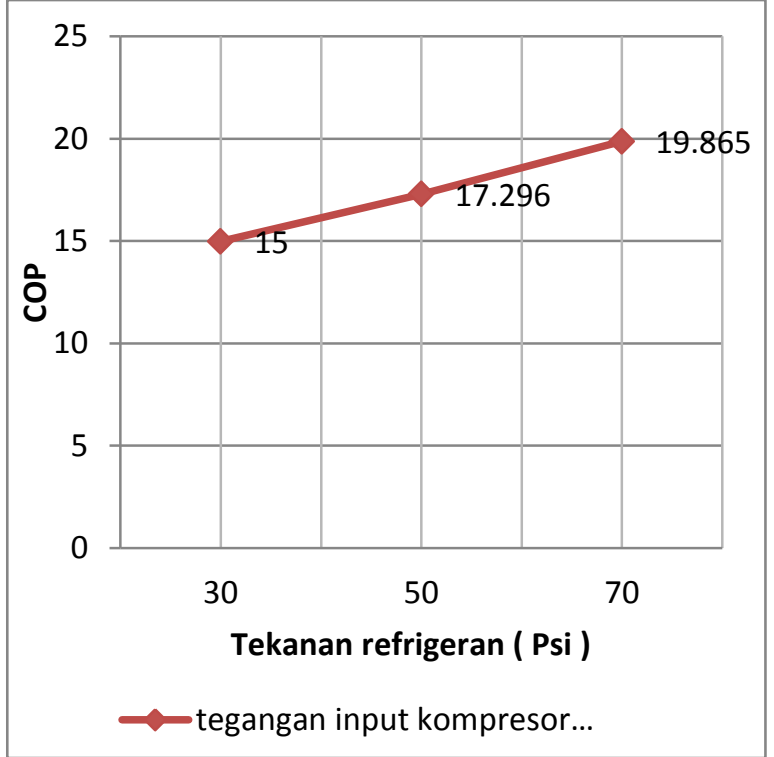

Gambar 4. Diagram nilai COP pada tekanan refrigeran yang berbeda

Pada tegangan input kompresor $200 \mathrm{~V}$ membutuhkan waktu 62 menit agar tercapai suhu ruangan $23{ }^{0} \mathrm{C}$. Kelembaban ruangan hanya mencapai $70 \%$. Sistem bekerja pada suhu pengembunan $52{ }^{\circ} \mathrm{C}$ dan suhu penguapan $12^{0} \mathrm{C}$

Pada tegangan input kompresor $210 \mathrm{~V}$ membutuhkan waktu 55 menit agar tercapai suhu ruangan $23{ }^{\circ} \mathrm{C}$. Kelembaban ruangan hanya mencapai $70 \%$. Sistem bekerja pada suhu pengembunan $49{ }^{\circ} \mathrm{C}$ dan suhu penguapan $12^{\circ} \mathrm{C}$.

Saat mesin pendingin bekerja, temperatur terendah terjadi pada input evaporator dan temperatur tertinggi terjadi pada output kompresor atau input kondensor. Pada sekitar menit ke 20 awal, refrigeran yang ditampung pada accumulator mencapai titik beku sehingga terjadi bunga es pada bagian luar accumulator, namun hal ini tidak berlangsung lama yaitu sekitar 15-20 menit.

Pada tegangan input kompresor $220 \mathrm{~V}$ membutuhkan waktu 50 menit agar tercapai suhu ruangan $23{ }^{0} \mathrm{C}$. Kelembaban ruangan mencapai 68\%. Sistem bekerja pada suhu pengembunan $15{ }^{\circ} \mathrm{C}$ dan suhu penguapan $50^{\circ} \mathrm{C}$.

Pada tegangan input kompresor $230 \mathrm{~V}$ membutuhkan waktu 48 menit agar tercapai suhu ruangan $23^{\circ} \mathrm{C}$. Kelembaban ruangan mencapai 68\%. Sistem bekerja pada suhu pengembunan $49{ }^{\circ} \mathrm{C}$ dan suhu penguapan $13^{\circ} \mathrm{C}$.

Pada tekanan refrigeran 70 Psi membutuhkan waktu 50 menit agar tercapai suhu ruangan $23^{\circ} \mathrm{C}$. Kelembaban ruangan 
mencapai 68\%. Sistem bekerja pada suhu pengembunan $50{ }^{\circ} \mathrm{C}$ dan suhu penguapan $15^{\circ} \mathrm{C}$.

Pada tekanan refrigeran 50 Psi membutuhkan waktu 100 menit agar tercapai suhu ruangan $23^{\circ} \mathrm{C}$. Kelembaban ruangan mencapai 68\%. Sistem bekerja pada suhu pengembunan $53{ }^{\circ} \mathrm{C}$ dan suhu penguapan $13{ }^{\circ} \mathrm{C}$.

Pada tekanan refrigeran 30 Psi sampai pada waktu 100 menit hanya konstan suhu ruangan $26{ }^{\circ} \mathrm{C}$. Kelembaban ruangan hanya mencapai $69 \%$. Sistem bekerja pada suhu pengembunan $52{ }^{\circ} \mathrm{C}$ dan suhu penguapan 11 ${ }^{0} \mathrm{C}$.

Data dan hasil perhitungan diatas menunjukkan bahwa input tegangan kompresor yang paling baik adalah $220 \mathrm{~V}$ dengan menghasilkan COP sebesar 19,865; sedangkan untuk tekanan refrigeran yang paling baik adalah pada tekanan refrigeran 70 Psi dengan menghasilkan COP sebesar 19,865.

\section{KESIMPULAN}

Berdasarkan pembahasan pada bab sebelumnya dapat disimpulkan bahwa :

1. Semakin kecil tegangan input kompresor membuat nilai COP menurun masingmasing 17,855 dan 16,87 pada tegangan input kompresor $210 \mathrm{~V}$ dan $200 \mathrm{~V}$. Nilai COP paling tinggi didapat pada input tegangan kompresor 220V yaitu mencapai 19,865; dan pada tegangan $230 \mathrm{~V}$ COP kembali turun menjadi 18,23. Semakin rendah tekanan refrigeran juga membuat nilai COP menurun. COP sebesar 19,865 pada tekanan refrigeran 70Psi, 17,296 pada tekanan refrigeran 50Psi, dan 14,980 pada tekanan refrigeran $30 \mathrm{Psi}$,

2. Perubahan temperatur yang terjadi pada evaporator dan kondensor yaitu masingmasing $12^{\circ} \mathrm{C}$ dan $52^{\circ} \mathrm{C}$ pada tegangan input kompresor $200 \mathrm{~V}, 12^{\circ} \mathrm{C}$ dan $49^{\circ} \mathrm{C}$ pada tegangan input kompresor $210 \mathrm{~V}, 15^{\circ} \mathrm{C}$ dan $50^{\circ} \mathrm{C}$ pada tegangan input kompresor $220 \mathrm{~V}$, $13^{\circ} \mathrm{C}$ dan $50^{\circ} \mathrm{C}$ pada tegangan input kompresor $230 \mathrm{~V}, 15^{\circ} \mathrm{C}$ dan $50^{\circ} \mathrm{C}$ pada tekanan refrigeran $70 \mathrm{Psi}, 13^{\circ} \mathrm{C}$ dan $53^{\circ} \mathrm{C}$ pada tekanan refrigeran $50 \mathrm{Psi}$, dan $11^{\circ} \mathrm{C}$ dan $58^{\circ} \mathrm{C}$ pada tekanan refrigeran $30 \mathrm{Psi}$.

\section{DAFTAR PUSTAKA}

1. Arismunandar, Wiranto. H.Saito. 1991. Penyegaran Udara. Edisi keempat, PT. Pradnya Paramita, Jakarta.
2. Hara,Supratman.Stocker,W.f.,Jones,J.W. 1982. Refrigerasi Dan Pengkondisian Udara, Edisi Kedua, Erlangga, Jakarta..

3. Reynolds, Wilbert F. dan W. Jones, Jerold. 1991. Thermodinamika Teknik. Edisi kedua.

4. Terjemahan Filipno Harahap. Penerbit Erlangga. Jakarta.

5. Ridwan. 1994. Teknik Pendingin. Gunadarma. Depok.

6. Sudjito, Saifuddin Baedoewie, Agung Sugeng, Diktat Termodinamika Dasar, Jakarta, Indonesia. 